\title{
Guidelines for the appropriate use of genetic tests in infertile couples
}

\author{
Carlo Foresta $^{\star, 1}$, Alberto Ferlin ${ }^{1}$, Luca Gianaroli ${ }^{2}$ and Bruno Dallapiccola ${ }^{3}$ \\ ${ }^{1}$ University of Padova, Department of Medical and Surgical Sciences, Clinica Medica 3, Via Ospedale 105, 35128 \\ Padova, Italy; ${ }^{2}$ SISMER, Via Mazzini 12, 40138 Bologna, Italy; ${ }^{3}$ University of Rome "La Sapienza", Institute of \\ Medical Genetics and Institute CSS-Mendel, Viale Regina Margherita 261, 00198, Roma, Italy
}

Research on genetic causes of male and female infertility rapidly expanded in the last years, following the development of in vitro fertilising techniques. Genetic tests are now available to explore the cause of the infertility and assess the risk of a given couple to transmit its genetic characteristics. This allows at-risk couples to take an informed decision when electing for a medically assisted reproduction. It also allows the professionals to offer a prenatal diagnosis when appropriate. Thus, the genetic work-up of the infertile couple has become good practice for an appropriate diagnosis, treatment and prognostic assessment. The lack of national or international rules for the genetic approach to the infertile couple, prompted the Italian community of professionals in the field of reproductive medicine to join and set up guidelines for the genetic diagnosis of male and female infertility. The group of clinical and research experts is representative of 12 national scientific societies and was supported by external experts from four international societies. We examine the clinically relevant genetic causes of male and female infertility and suggest the category of patients for which each genetic test is recommended or optional, both for an accurate diagnosis and prior to ART.

European Journal of Human Genetics (2002) 10, 303 - 312. doi:10.1038/sj.ejhg.5200805

Keywords: female infertility; genetics; male infertility; mutations

\section{Introduction}

Infertility is a major health problem, as in the western countries it affects about $15 \%$ of couples trying for a child. ${ }^{1-5}$ Despite the prevalence of infertility, only recent research has focused onto genetic factors accounting for both male and female infertility. It can be speculated that in about $15 \%$ of male and $10 \%$ of female infertile subjects genetic abnormalities could be present, including chromosome aberrations and single gene mutations. Some genetic factors have been outlined and a number of genes related to infertility have been cloned, while other genes have been assigned to specific chromosome regions, but the majority of them still remain

\footnotetext{
*Correspondence: Prof C Foresta, University of Padova, Department of Medical and Surgical Sciences, Clinica Medica 3, Via Ospedale 105, 35128 Padova, Italy. Tel: +39 049 8212639; Fax: +39 049 657391; E-mail: forestac@protec.it

Received 1 November 2001; revised 6 March 2002; accepted 15 March 2002
}

undeciphered. Genetic research has expanded in the last years, following the development of in vitro fertilising techniques. Genetic tests are now available to explore the cause of the infertility and assess the risk of a given couple to transmit its genetic characteristics. This allows at-risk couples to take an informed decision when electing for a medically assisted reproduction. It also permits the professionals to offer a prenatal diagnosis when appropriate. The use of intracytoplasmic sperm injection ${ }^{6}$ (ICSI) has raised major concerns about safety for the offspring, since it bypasses the physiological mechanisms related to fertilisation. Natural selection prevents the transmission of mutations causing infertility, while this protective mechanism is overcome by the assisted reproduction techniques (ART). The risk is therefore that genetic cause of infertility increases in future generations, as demonstrated for male infertility. ${ }^{7}$ Thus, the identification of genetic factors in the infertile couple has become good practice for appropriate management of the infertile couple. 
The lack of national or international rules for the genetic approach to the infertile couple, prompted the Italian community of professionals in the field of reproductive medicine to set up guidelines for the genetic diagnosis of male and female infertility. The group of clinical and research experts includes the different disciplines involved in human reproduction (gynaecology, andrology, endocrinology, biology of reproduction, urology, embryology and genetics) (Table 1). Twelve national scientific societies nominated one representative to take part on the working group (Committee). This Committee worked for five months mainly by reviewing the literature, each participant preparing schemes that were discussed by the Committee. In February 2001 the results were also discussed at a national congress attended by external experts from four international societies. The conclusive draft was displayed on the Internet for a 4-month period to allow further comments by the entire Italian scientific community, based on how the final document was prepared by the Authors.

The main goal of the Guidelines is to promote the appropriate use of the available genetic tests. Using these Guidelines, together with careful genetic counselling would provide a better diagnosis and management of the infertile couple. However, it should be kept in mind that genetic tests are part of the diagnostic workup of the infertile couple, and therefore other investigations should be performed first. ${ }^{8}$

The Guidelines have been prepared not to include all the genetic causes of infertility, but only those clinically relevant, both in terms of prevalence and risk of transmission. Therefore, genetic syndromes in which infertility is only an accompanying manifestation have not been included, since in these disorders the infertility clinicians are playing only a minor or lesser role. Furthermore, the Guidelines are intended for the management of the infertile couple by the clinicians and have not evaluated technical aspects of the diagnostic test. The Committee has suggested some genetic tests as strongly recommended, while others have been considered optional or not ready for routine clinical use.

\section{Summary of recommendations for the use of genetic tests in male and female infertility}

The following paragraphs review the genetic tests that are recommended by the Committee, and are summarized in Tables 2 and 3 . The rationale for these recommendation is presented in the next section. Male infertility has been classified on the basis of the seminal analysis ${ }^{9}$ although infertility and alterations of seminal characteristics are not synonymous. However, this classification is in keeping with the clinical practice, since the patients candidate to ART are often classified according to semen analysis. Genetic diagnosis and genetic counselling should always be part of an extensive evaluation of these patients, and basic clinical analysis should precede any genetic analysis. However, genetic evaluation is also recommended when infertility is apparently related to other obvious causes, since different causes may coexist. ${ }^{10}$ Similar to male infertility, female infertility has also been classified primarily on clinical criteria, especially abnormalities of the ovarian function resulting in abnormal menstrual cycle. Even if recurrent foetal loss is not actually a cause of primary infertility, it has been included, given its clinical relevance and frequency of genetic causes in this condition.

\section{Karyotype analysis}

Peripheral blood karyotype analysis is strongly recommended during the diagnostic workup of subjects with azoospermia and severe oligozoospermia. In these subjects the cytogenetic screening is mandatory prior to any ART procedure (including intrauterine insemination, IUI), also in

Table 1 List of participants to the Guidelines

\begin{tabular}{|c|c|}
\hline \multicolumn{2}{|l|}{ Italian scientific societies (Comittee) } \\
\hline Association of Extra-Hospital Gynaecologists (AGEO) & Prof F Giorgino (Padova) \\
\hline Italian Society of Andrology (SIA) & Prof V Mirone (Napoli) \\
\hline Italian Society of Embryology and Reproduction (SIER) & Prof G Ruvolo (Palermo) \\
\hline Italian Society of Endocrinology (SIE) & Prof A Fabbri (Roma) \\
\hline Italian Society of Fertility and Sterility (SIFES) & Prof G Simoni (Milano) \\
\hline Italian Society of Gynaecology and Obstetrics (SIGO) & Prof L Bovicelli (Bologna) \\
\hline Italian Society of Human Genetics (SIGU) & Prof B Dallapiccola (Roma) \\
\hline Italian Society of Medical Andrology (SIÁM) & Prof C Foresta (Padova) \\
\hline Italian Society of Pathophisiology of Reproduction (SIFR) & Prof B Baccetti (Siena) \\
\hline Italian Society of Reproduction (SIdR) & Prof G Ragni (Milano) \\
\hline Italian Society of Urologic, Andrologic and Nephrologic Ecography (SEIUN) & Prof C Trombetta (Trieste) \\
\hline Italian Society of Urology (SIU) & Prof A Franco (Torino) \\
\hline \multicolumn{2}{|l|}{ External experts from international societies } \\
\hline American Society of Andrology (ASA) & Prof P Patrizio (Philadephia) \\
\hline European Academy of Andrology (EAA) & Prof G Forti (Firenze) \\
\hline European Society of Human Reproduction and Embryology (ESHRE) & Prof L Gianaroli (Bologna) \\
\hline International Society of Immunology of Reproduction (ISIR) & Prof A Lenzi (Roma) \\
\hline
\end{tabular}


Table 2 Genetic tests in male infertility

\begin{tabular}{|c|c|c|c|}
\hline & Azoospermia & $\begin{array}{l}\text { Severe oligozoospermia } \\
\text { (sperm count }<10 \times 10^{6} / \mathrm{ml} \text { ) }\end{array}$ & $\begin{array}{l}\text { Moderate oligozoospermia } \\
\text { (sperm count } 10-20 \times 10^{6} / \mathrm{ml} \\
\text { and normozoospermia) }\end{array}$ \\
\hline Karyotype & $\begin{array}{l}\text { During diagnostic workup } \\
\text { Prior to ART }\end{array}$ & $\begin{array}{l}\text { During diagnostic workup } \\
\text { Prior to ART }\end{array}$ & $\begin{array}{l}\text { After } 1 \text { year of sexual } \\
\text { intercourse aimed at } \\
\text { pregnancy } \\
\text { Prior to ART }\end{array}$ \\
\hline $\begin{array}{l}\text { Microdeletions of the } \mathrm{Y} \\
\text { chromosome long arm }\end{array}$ & $\begin{array}{l}\text { During diagnostic workup } \\
\text { (non obstructive) } \\
\text { Prior to ART }\end{array}$ & $\begin{array}{l}\text { During diagnostic workup } \\
\text { Prior to ART }\end{array}$ & - \\
\hline CFTR & $\begin{array}{l}\text { During diagnostic workup } \\
\text { (CBAVD) } \\
\text { Prior to ART }\end{array}$ & $\begin{array}{l}\text { During diagnostic workup } \\
\text { (CUAVD) } \\
\text { Prior to ART }\end{array}$ & - \\
\hline KALI & $\begin{array}{l}\text { During diagnostic workup } \\
(\mathrm{HH})\end{array}$ & - & - \\
\hline Androgen receptor & $\begin{array}{l}\text { Suggested: } \\
\text { During diagnostic workup } \\
\text { (high ASI) }\end{array}$ & $\begin{array}{l}\text { Suggested: } \\
\text { During diagnostic workup } \\
\text { (high ASI) }\end{array}$ & - \\
\hline
\end{tabular}

ART: assisted reproduction techniques; ASI: androgen sensitivity index; CBAVD: congenital bilateral absence of vas deferens; CUAVD: congenital unilateral absence of vas deferens; HH: hypogonadotropic hypogonadism.

Table 3 Genetic tests in female infertility

\begin{tabular}{|c|c|c|c|c|}
\hline & $\begin{array}{l}\text { Amenorrhoea } \\
\text { (primary and secondary, } \\
\text { including POF) and } \\
\text { oligomenorrhoea with } \\
\text { hypergonadotropinism }\end{array}$ & $\begin{array}{l}\text { Hypogondatropic } \\
\text { hypogondism }\end{array}$ & Apparently normal & Recurrent foetal loss \\
\hline Karotype & $\begin{array}{l}\text { During diagnostic workup } \\
\text { Prior to ART }\end{array}$ & - & $\begin{array}{l}\text { After } 1 \text { year of sexual } \\
\text { intercourses aimed to } \\
\text { pregnancy } \\
\text { Prior to ART }\end{array}$ & During diagnostic workup \\
\hline KALI & - & During diagnostic workup & - & - \\
\hline CFTR & - & - & Prior to ART & - \\
\hline
\end{tabular}

ART: assisted reproduction techniques; POF: premature ovarian failure.

those cases in which sperm parameters are within the normal ranges or only slightly abnormal. Furthermore, since some karyotype anomalies (for example 47,XYY, some translocations and other structural aberrations) may cause male infertility associated with an apparent normozoospermia, this analysis should be performed when no result is reached after 1 year of sexual intercourse aimed at pregnancy.

The Committee has recommended karyotype analysis during the diagnostic workup of infertile women presenting with primary ovarian dysfunction or recurrent foetal loss. This screening is mandatory in women candidates to ART. Karyotype analysis should be included as diagnostic test, when no result is achieved after 1 year of sexual intercourse aimed at pregnancy.
Microdeletions of the long arm of the $\mathrm{Y}$ chromosome Yq microdeletion screening is strongly recommended during the diagnostic workup of infertile patients with non obstructive azoospermia and severe oligozoospermia, regardless of the presence of other apparent causes of testicular damage. This analysis is not indicated when sperm concentration is higher than 10 million/ml. Furthermore, all individuals with non obstructive azoospermia and severe oligozoospermia should be analysed for Yq microdeletions prior to any ART procedure.

\section{CFTR gene}

Screening for CFTR mutations (including the 5T allele) is strongly recommended in infertile individuals with a diagnosis of bilateral or unilateral congenital absence of vas 
deferens (CBAVD or CUAVD). Whenever the couple is planning a pregnancy by ART, this test should be performed in both the affected male and his partner.

Mutations in the CFTR gene have not been unequivocally associated with reduced female infertility. However, women affected by cystic fibrosis are subfertile and have a higher risk of complicated pregnancy. ${ }^{11}$ The prevalence of the CFTR mutation in the general population $(1: 25)$, and the higher probability of a CFTR mutation to occur in the male partners of ICSI couples, recommend this test in the female partners candidate to ART. ${ }^{12}$

\section{KAL1 gene-Kallmann syndrome}

Although Kallmann syndrome is rare and mutation analysis of KAL1 gene is not easily available, the Committee has recommended the inclusion of the KAL1 gene screening in all azoospermic men with hypogonadotropic hypogonadism (HH) and anosmia. Kallmann syndrome should be suspected, and KAL1 gene analysis performed, only in women with $\mathrm{HH}$. Autosomal recessive and dominant causes of $\mathrm{HH}$ may be present, but the genes responsible for these conditions are to date unknown. ${ }^{13}$

\section{Androgen receptor gene}

The Committee has suggested this test in azoospermic and severely oligozoospermic men with high androgen sensitivity index (ASI), although this is not a mandatory rule. Furthermore, in these cases the test should be performed as a second step, following karyotype analysis. Obviously, when other clinical manifestations of androgen insensitivity are present, the AR gene should be screened for mutations. Contrasting data have been reported concerning the role of the CAG triplet expansion in male infertility. Therefore, at present this analysis should not be performed in the clinical practice.

\section{$5 \alpha$-reductase-2 gene (SRD5A2)}

Given the low incidence of $5 \alpha$-reductase deficiency in infertile males, the Committee has suggested this analysis only in selected subjects presenting clinical features fitting with this disorder.

\section{Aneuploidy analysis in spermatozoa}

At present there is not an agreement on the clinical application of fluorescent in situ hybridisation (FISH) for the analysis of chromosome content in individual spermatozoa, and the Committee has suggested that this test should not be performed as a routine analysis in infertile males. Once more robust scientific data becomes available, FISH analysis could be indicated in primary severe testiculopathies and after chemo-radiotherapy.

\section{Fragile $\mathrm{X}$ syndrome}

This test is strongly recommended during the diagnostic workup of women with oligo-amenorrhoea caused by primary ovarian dysfunction (including preamture ovarian failure, POF), especially when ART is considered. Furthermore, screening should also be performed when no obvious abnormality is present but poor response to ovarian stimulation in ART cycles was noticed. A careful genetic counselling should be offered to patients carrying premutation and candidate to ART, as premutation is predisposing to further expansion of the repeat in the germ line. Therefore premutated women are at high risk of delivering male children with mental retardation. In these cases, preimplantation diagnosis for fragile $\mathrm{X}$ syndrome should be offered. ${ }^{14}$

\section{Background for the guidelines Male infertility}

Knowledge of the molecular mechanisms underlying male infertility is rapidly expanding, and it is likely that many more genes affecting male reproduction will be identified in the next few years. As a result of the most recent researches, many genetic anomalies have been recognised as clinically relevant, both in determining male infertility and as risk factors of transmission by ART. These defects include chromosomal aberrations and specific gene mutations. In addition, other gene mutations (ie, $\beta$-subunit of LH, FSH, FSH and $\mathrm{LH}$ receptors, other genes involved in early sexual development) appear to have only a minor clinical role and further studies are needed. The present Guidelines do not consider these mutations, although they could be included in the future, once scientific evidence will prove their role. Table 4 summarises the genetic causes of male infertility.

Karyotype analysis It has been known for some 20 years ${ }^{15}$ that the prevalence of chromosome abnormalities is higher in infertile men, this figure being inversely related to the sperm count. Chromosomal aberrations are also more common in the male partner of couples seeking ICSI, compared to the general population. ${ }^{16-18}$ Based on the largest published series it could be estimated that the overall incidence of a chromosomal factor in infertile males ranges between 2 and $8 \%$, with a mean value of $5 \% .^{15-27}$ This value is increasing to about $15 \%$ in azoospermic males, being largely contributed by patients with 47,XXY aneuploidy. Sex chromosomes abnormalities are predominating, but a wide range of structural autosomal anomalies (Table 4) are also found. Heteromorphisms should be regarded as common variations devoid of any clinical relevance. Sex chromosome abnormalities were found in $3.7 \%$, and autosomal abnormalities in $2.4 \%$ of infertile males seeking ICSI programmes in France. ${ }^{17}$ Sex chromosome anomalies were found in $15.9 \%$, and autosomal anomalies in $2.8 \%$ of the azoospermic men. Notably, the corresponding figure in the normozoospermic infertile men was $3.0 \%$, including both sex chromosome aneuploidies (ie, 47,XYY, mosaicisms) (1.4\%) and balanced structural abnormalities (1.6\%). Preliminary results on pregnancies conceived through ICSI suggest that sex chromo- 
Table 4 Classification of genetic causes of male infertility

\begin{tabular}{l} 
Chromosome aberrations (homogenous or mosaicism) \\
Sex chromosomes \\
$47, X X Y$ (Klinefelter syndrome) \\
$47, X Y Y$ and other YY-aneuploidies \\
$46, X X$ and $45, X$ males \\
Structural Y chromosome aberrations \\
Deletions \\
Rings \\
Isochromosomes \\
Inversions \\
Translocations \\
Autosomes \\
Translocations (Robertsonian, reciprocal) \\
Inversions \\
Other structural abnormalities (inversions, ESACs (Extra \\
Satellite Marker Chromosomes)) \\
Clinical syndromes \\
Trisomy 21 \\
Partial duplications and deletions \\
Chromosomal heteromorphisms \\
Inv(9) \\
Familial inversion of the Y \\
Yq+ \\
Increased/reduced pericentromeric constitutive \\
heterochromatin \\
Large-sized/duplicated satellites on acrocentric chromosomes \\
Gene mutations \\
Y-linked \\
Microdeletions Yq11 \\
X-linked \\
Kallmann syndrome \\
Androgen insensitivity syndrome/Kennedy disease \\
Autosomal \\
Complex genetic syndromes in which fertility is a minor \\
manifestation (such as, miotonic dystrophy or $5 \alpha$ reductase \\
deficiency) \\
Infertility as major manifestation \\
CFTR \\
Genes for $\beta$-subunit of LH and FSH and genes for LH and \\
FSH receptors \\
Chromosomal alterations confined to sperms \\
Following radio-chemotherapy \\
\hline
\end{tabular}

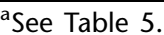

some anomalies may be more frequent than in the naturally occurring pregnancies. In general, children conceived by ICSI have an increased risk of an abnormal karyotype. ${ }^{28-30}$ Although data are still controversial, a figure of about 3\% has been suggested, half of them being transmitted by a chromosomally abnormal prospective father.

Microdeletions of the long arm of the Y chromosome Since the original report, ${ }^{31}$ many studies have proved that Yq microdeletions are a common cause of male infertility. ${ }^{10}$ Three different spermatogenesis loci were assigned to this region, which are referred to as 'azoospermia factors' (AZFa, b and $\mathrm{c}$ ), and different candidate genes have been mapped: USPY9 and DBY in AZFa, ${ }^{32}$ RBMY1 in $\mathrm{AZFb},{ }^{33}$ and DAZ in AZFc. ${ }^{34}$ However, other Yq genes have been isolated and their contribution to the AZF phenotype is still unknown. ${ }^{35,36}$
Microdeletions determine a severe primary testiculopathy resulting in azoospermia or severe oligozoospermia, and they are more frequent in the AZFc locus. Although heterogeneous results have been published, the overall prevalence of Yq microdeletions in the infertile males can be estimated as about $10 \%{ }^{10}$ In selected infertile males this figure is increasing to $15 \%$ in subjects with idiopathic severe oligozoospermia and up to $20 \%$ in those with idiopathic non-obstructive azoospermia. Individuals presenting with severe testiculopathies associated with other manifest causes of testicular damage, such as varicocele or cryptorchidism, may also have Yq microdeletions. ${ }^{37-39}$

Patients with Y chromosome deletions frequently have sperm either in the ejaculate or within the testis, and are therefore suitable candidates for ART. In these cases, the genetic anomaly is invariably transmitted to the male sons, ${ }^{40}$ who also receive the paternal disorder (ie, infertility). However, the actual consequences of this transmission are still unclear. Moreover, recent studies on lymphocytes and spermatozoa of male patients carrying a Yq microdeletion, report an association with an increased number of somatic cells as well as gametes lacking the $\mathrm{X}$ chromosome, which, if confirmed, could lead to the birth of 45 , X female children. ${ }^{41}$

CFTR gene Cystic fibrosis is one of the most common autosomal recessive disease among Caucasians, affecting one in 2500 live births, while one in 25 individuals is an asymptomatic heterozygote. The most frequent CFTR gene mutation (mapping to chromosome $7 \mathrm{q} 31.1-31.2$ ), is the $\Delta \mathrm{F} 508$, but more than 900 different mutations have been identified (see website: www.genet.sickkids.on.ca/cftr). CBAVD in most cases is regarded as a mild or incomplete form of cystic fibrosis. About $80 \%$ of these men are heterozygous, compound heterozygotes for a CFTR mutation or they carry the so called ' $5 \mathrm{~T}$ allele'. ${ }^{42-45}$ This distinct mutation causes the skipping of exon 9 and low levels of expression of the CFTR protein. Among patients with CBAVD, about $20 \%$ have mutations in one copy of CFTR, $20 \%$ have mutations in both copies of CFTR (compound heterozygotes), $30 \%$ have a mutation in one copy of CFTR and the 5 T allele in the other CFTR gene, and 10\% are carrying only the 5T allele. Also CUAVD has been ascribed to CFTR mutations; although the prevalence of mutation in this group of subjects is widely ranging in different studies $(11-75 \%) .{ }^{45-47}$ Therefore, the clinical manifestation of individuals with CFTR mutations could be both azoospermia and oligozoospermia associated with CBAVD or CUAVD, respectively. Spermatogenesis is normal, and therefore they are strong candidates to ICSI using sperm retrieved from testis or epididymis. ${ }^{48}$ In these cases the major risk to offspring is fullblown cystic fibrosis, in those couples in which the female partner is heterozygous for a CFTR mutation. ${ }^{49}$

KAL1 gene Kallmann syndrome affects one in 10000 males, and consists of congenital, isolated, idiopathic 
hypogonadotropic hypogonadism $(\mathrm{HH})$ associated with anosmia. Isolated $\mathrm{HH}$ without anosmia can occur as an isolated symptoms or in association with a wide range of somatic abnormalities, resulting from different genetic mutations. ${ }^{50}$ Three different forms of Kallmann syndrome do exist, inherited as X-linked, autosomal dominant or recessive traits. The X-linked form (KAL1 gene) causes 10$15 \%$ of Kallmann syndrome cases. ${ }^{13,50}$ Additional clinical features in these subjects include cryptorchidism, unilateral renal agenesis, cleft palate, and colour blindness. Hormonal treatment may restore fertility ${ }^{51}$ in Kallmann's subjects and, in turn, risk of transmitting the mutation to offspring.

Androgen receptor gene Androgen insensitivity syndrome is an X-linked recessive disorder due to a defect in the androgen receptor (AR) gene located in Xq11-12. Affected individuals may show variable phenotypes, ranging from full-blown female appearance, to overt genital ambiguity, or even infertile male. ${ }^{52}$ Over 300 different mutations have been reported (http//www.mcgill.ca/androgendb/), the majority of which representing point mutations leading to aminoacid substitutions. Infertile males carrying AR gene mutations show azoospermia or severe oligozoospermia, either as an isolated feature or in association with other anomalies resulting from defective sensibility to androgens (such as cryptorchidism, hypospadia, gynaecomastia, poor virilisation). They also exhibit distinct hormonal profile, with increased LH levels and normal-high testosterone plasma concentrations. The product of $\mathrm{LH} \times$ testosterone (expressed in $\mathrm{U} \times \mathrm{nmol} / \mathrm{l}^{2}$ ), also referred to as androgen sensitivity index (ASI), can be useful for detecting patients at risk for AR gene mutation. ${ }^{53}$ The frequency of point mutations in the AR gene in infertile subjects with azoospermia or severe oligozoospermia is estimated in $2-3 \% .{ }^{53}$ Since identical mutations in AR gene may be associated with different phenotypes, the consequences in children born by use of ART cannot be easily predictable and the couple should be informed about the possibility of a worsening of the clinical features in offspring inheriting the disease-gene.

Large expansion (more than 40) of the trinucleotide (CAG) repeat in exon 1 causes spinal bulbar muscular atrophy (SBMA or Kennedy disease). It is still unclear if minor CAG repeat expansions result in isolated defective spermatogenesis. ${ }^{54,55}$ It should be kept in mind that the use of sperm from these male patients will not lead to affected children since boys will not inherit the mutation and girls will be unaffected carriers; however, in the next generation these carrier girls will be at risk to generate affected boys.

$5 \alpha$-reductase-2 gene (SRD5A2) This enzyme converts testosterone to $5 \alpha$-dihydrotestosterone in specific androgendependent target tissues. ${ }^{56}$ Deficiency of $5 \alpha$-reductase- 2 causes male pseudohermaphroditism usually presenting with pseudovaginal perineoscrotal hypospadia at birth. Virilisation occurs at puberty with phallic growth and testicular descent. Adult subjects may present with azoospermia or severe oligozoospermia sometimes associated with undescended testes and hypospadia. ${ }^{57,58}$ Pregnancy by IUI has been reported in patients with $5 \alpha$-reductase deficiency. ${ }^{58}$

Aneuploidy analysis in spermatozoa Normal males produce a variable proportion of spermatozoa (ranging between 1 and 15\%) with visible chromosome aberrations, most of them being of the structural type (about 90\%). ${ }^{59}$ Some evidence suggests that a number of clinical conditions related to male infertility are associated with increased numbers of hypo- or hyperaploid spermatozoa. In infertile patients with severe testiculopathies numerical sperm anomalies are increased as a consequence of mitotic and meiotic failures. $^{60-62}$ Furthermore, chemotherapy and radiotherapy have a clastogenic effect persisting over a period of time (up to 6 months) after discontinuing these treatments. ${ }^{63,64}$ FISH, which is the technique of choice for assessing the sperm aneuploidies, has some limitations, above all because it is unable to detect structural abnormalities. In addition, only a limited number of spermatozoa are evaluated, standardization of the hybridization procedure is needed and automation is currently lacking.

Other conditions Other genetic anomalies have been evaluated by the Committee, but have not been included as tests for routine assessment of the infertile subjects, either because they are extremely rare in the setting of an infertility centre, or because scientific data are still limited. They include mutations in genes essential for gonadal development and testicular function (deficiency of steroidogenic enzymes, mutations in the genes for $\beta$-subunit of $\mathrm{LH}$ and FSH, and LH and FSH receptors), and pleiotropic genes whose mutation also alter spermatogenesis (miotonic dystrophy, DAX1). Furthermore, a number of genetic disorders may affect spermatogenesis, but clinical manifestations are so complex that infertility represents a minor feature (Table 5). Furthermore, some forms of male infertility characterised by uniform and permanent morphological and structural alterations of the entire sperm population (such as round headed sperm, miniacrosome etc.) are probably the results of hitherto unknown genetic mutations. ${ }^{65}$ This aspect should be kept in mind in subjects candidate to ART.

\section{Female infertility}

Following the progress of molecular biology, many studies have been undertaken in recent years to clarify the genetic mechanisms underlying female reproductive disorders. Apart from chromosomal abnormalities, alterations in female sexual maturation or reproductive function may be caused by gene defects at various levels of the hypothalamicpituitary-ovarian axis or in gonadal and adrenal steroid biosynthesis or reception. ${ }^{66}$ Moreover, the possibility of single or multiple gene defects in common clinical conditions, such as polycistic ovary syndrome (PCOS) ${ }^{67,68}$ or 
Table 5 Rare cases of male infertility, or syndromes in which infertility is a minor manifestation

Miotonic dystrophy

$5 \alpha$-reductase 2 deficiency

Steroidogenic enzymes deficiency (21 $\alpha$-hydroxilase and others)

Bardet-Biedl

Noonan

Prader-Willi

Cerebellar ataxia with hypogonadotropic hypogonadism

Fanconi anaemia

Prune-Belly

Homozygous $\beta$-thalassemia

Hemochromatosis

premature ovarian failure (POF), ${ }^{69}$ have been recently described. Technical progresses in ART have stimulated research in this field. As a consequence, some clinical aspects specifically related to these techniques, such as poor response to ovarian stimulation, have been investigated as genetically determined. Finally, a causal relationship has been established between many chromosomal abnormalities and the spontaneous early foetal demise. ${ }^{70,71}$ In Table 6 the genetic causes of female infertility have been summarised.

Karyotype analysis Turner syndrome is the most common chromosome abnormality in infertile women, but also a variety of structural autosomal aberrations may be found with relatively high frequency. Contradictory data have been published concerning the frequency of chromosomal abnormalities in female infertility, ${ }^{16,18,24,72}$ which, can be estimated in about $5 \% .{ }^{17}$ In the female partners of couples undergoing the ICSI procedure, $2.8 \%$ has numerical sex chromosome abnormalities and 2.1\% structural autosomal abnormalities. ${ }^{17}$ The phenotype of women affected by sex chromosomal aberrations is highly variable, in terms of external and internal genitalia and physical features. However, a feature shared by all these chromosome imbalances is primary ovarian dysfunction (hypergonadotropic) with primary or secondary amenorrhoea (including POF) or oligomenorrhoea. For example, about $30 \%$ of primary amenorrhoeas are caused by Turner syndrome. In addition, autosomal structural abnormalities may cause recurrent foetal loss. ${ }^{73}$ Abnormal karyotype (such as 47,XXX) may be found in women without apparent causes of infertility. ${ }^{17}$ Many women with chromosomal abnormalities, including Turner syndrome, may become pregnant by use of ART.

Fragile $X$ syndrome (FRAXA) This is the most common cause of mental retardation in males and it is caused by the expansion of the CGG trinucleotide repeat in exon 1 of the FMR1 gene located in Xq27.3. In the general population less than 50 repeats are found, while more than 200 (full mutation) are causing mental retardation. A premutation is defined as 50-200 repeats and can be associated with POF in otherwise normal women. In fact, $15-25 \%$ of premutated
Table 6 Classification of genetic causes of female infertility

Chromosomal aberrations (homogenous or mosaicism)

Sex chromosomes

Turner syndrome and gonadal dysgenesis with short stature (45,X; mosaicisms such as $45, X / 46, X X$ and $45, X / 47, X X X$; $X q$ isochromosome; $\operatorname{del}(X q)$; $\operatorname{del}(X p) ; r(X)$; etc)

Gonadal dysgenesis with $Y$-cell line Mixed dysgenesis (45, $X / 46, X Y)$

$46, X Y$ gonadal dysgenesis (Swyer syndrome)

True hermaphroditism with Y-cell line

$X$-autosomal translocation

47, XXX and mosaicisms

Autosomes

Robertsonian translocations

Reciprocal translocations

Inversions

Gene mutations

X-linked

Fragile $X$ syndrome (FRAXA)

Kallmann syndrome

Complete androgen insensitivity syndrome

Autosomal

Complex genetic syndromes in which fertility is a minor manifestation ${ }^{\mathrm{a}}$

Infertility as major manifestation

Genes for $\beta$-subunit of FSH and genes for $\mathrm{LH}$ and FSH receptors

Gene for GnRH receptor

BPES (blepharophimosis, ptosis, epicanthus inversus)

Danys-Drash syndrome

Fresier syndrome

Chromosomal aberrations confined to oocytes

Advanced age

asee Table 7.

women are affected by POF and $6.5 \%$ of women with POF carry a FRAXA premutation. ${ }^{74,75}$ Patients who will develop a POF frequently show a period of oligomenorrhoea with a progressive increase in gonadotropins. ${ }^{76}$ Furthermore, premutation has been shown to be associated with low response to ovarian stimulation during in vitro ART. ${ }^{77}$

KAL1 gene Kallmann syndrome due to mutation in the KAL1 gene is exceedingly rare in women, resulting in primary amenorrhoea with hypergonadotropinism and anosmia. A higher incidence of uterine malformations has been also reported. ${ }^{78}$ Heterozygous females have no discernible abnormalities. ${ }^{13}$

Other conditions Similarly to the males, other genetic conditions may determine female infertility. ${ }^{79,80}$ However, they are very rare and of little clinical relevance for specialists in the field of reproduction. Notable examples include androgen receptor gene mutations causing complete androgen insensitivity syndrome, syndromes in which infertility is a minor manifestation (Table 7), and syndromes in which infertility represents the major phenotype (mutations in FSH and $\mathrm{LH}$ receptors, FSH gene, GnRH receptor).

It is worth noting that karyotypically normal women produce a variable percentage (more than 20\%) of chromo- 
Table 7 Rare causes of female infertility, or syndromes in which infertility is a minor manifestation

\section{Galactosemia}

Mucopolysaccaridoses

Miotonic dystrophy

Prader-Willi

$21 \alpha$-hydroxilase, $17 \alpha$-hydroxilase and other steroidogenic

enzymes deficiency

Aromatase defect

Homozygous $\beta$-thalassemia

Cystic fibrosis

Hemochromatosis

DAX1 gene mutations

somally abnormal oocytes. This percentage is increasing with advanced maternal age, as a consequence of altered crossingover and increased non-disjunction. Therefore genetic counselling is especially recommended when ART is performed in older women.

\section{Conclusions}

These Guidelines are mainly intended for those specialists working in clinical settings related to male and female infertility, in order to have an appropriate use of the genetic tests that are currently available. The main goal of our work was to give recommendations concerning the tests that should be performed according to the different situations. The principles that led us to prepare these recommendations reside in the fundamental aims that specialists in this field should always bear in mind: (1) the need for a careful diagnosis of the infertility status and (2) the evaluation of the risk for the child to be born after ART and the appropriate management of the pregnancy to be obtained. We did not consider all the possible genetic causes of reproductive disorders, as well as technical aspects of each diagnostic genetic test, as these were not our intentions. Genetic counselling should be offered to all couples undergoing ART and it is further strongly recommended when a genetic anomaly is found in either one component of the couple. ${ }^{81}$ The final decision whether to have a test should be left to the patients, and it is the couple's decision regarding whether or not to proceed with ART. These decisions can be taken once the patients have clearly understood the genetic risks and possible consequences when ART is used. With genetic counselling and genetic testing, the cost of ART procedures would rise, but the patients would benefit from more fully informed decisions. ${ }^{81,82}$

\section{Acknowledgments}

The financial support of Telethon-Italy (grant no. E.C0988 to Carlo Foresta) and of University of Padova (to Alberto Ferlin) is gratefully acknowledged.

\section{References}

1 Greenhall E, Vessey M: The prevalence of subfertility: a review of the current confusion and a report of two new studies. Fertil Steril 1990; 54: 978 - 983.

2 Bhasin S, de Kretser DM, Baker HWG: Clinical review 64: pathophysiology and natural history of male infertility. J Clin Endocrinol Metab 1994; 79: 1525-1529.

3 Howards SS: Treatment of infertility. N Engl J Med 1995; 332 : $312-317$

4 Dawson C, Whitfield H: Subfertility and male sexual dysfunction. Br Med J 1996; 312: $902-905$.

5 de Kretser DM: Male infertility. Lancet 1997; 349: 787-790.

6 Palermo G, Joris H, Devroey p, Van Steirtheghem AC: Pregnancies after intracytoplasmic injection of single spermatozoon into an oocyte. Lancet 1992; 340: 17-18.

7 Faddy MJ, Silber SJ, Gosden RG: Intra-cytoplasmic sperm injection and infertility. Nature Genet 2001; 29: 131.

8 The ESHRE Capri Workshop Group: Optimal use of infertility diagnostic tests and treatments. Hum Reprod 2000; 15: 723 - 732

9 World Health Organization: WHO laboratory manual for the examination of human semen and sperm-cervical mucus interaction. Cambridge: Cambridge University Press, 1999.

10 Foresta C, Moro E, Ferlin A: Y chromosome microdeletions and alterations of spermatogenesis. Endocrine Rev 2001; 22: $226-$ 239.

11 Cohen LF, Saint'Agnese DI, Friedlander J et al: Cystic fibrosis and pregnancy - A national survey. Lancet 1980; 2: 842-844.

12 Lewis-Jones DI, Gazvani MR, Mountford R: Cystic fibrosis in infertility: screening before assisted reproduction: opinion. Hum Reprod 2000; 15: 2415 - 2417.

13 Oliveira LM, Seminara SB, Beranova $M$ et al: The importance of autosomal genes in kallmann syndrome: genotype-phenotype correlations and neuroendocrine characteristics. J Clin Endocrinol Metab 2001; 86: 1532-1538.

14 Sermon K, Seneca S, Vanderfoeillie A et al: Preimplantation diagnosis for fragile $\mathrm{X}$ syndrome based on the detection of the non expanded paternal and maternal CGG. Prenat Diagn 1999; 19: $1223-1230$.

15 Chandley AC: The chromosomal basis of human infertility. $\mathrm{Br}$ Med Bull 1979; 35: 181-186.

16 Peschka B, Leygraaf J, van der Ven K et al: Type and frequency of chromosome aberrations in 781 couples undergoing intracytoplasmic sperm injection. Hum Reprod 1999; 14: $2257-2263$.

17 Gekas J, Thepot F, Turleau C et al: Chromosomal factors on infertility in candidate couples for ICSI: an equal risk of constitutional aberrations in women and men. Hum Reprod 2001; 16: $82-90$.

18 Meschede D, Lemcke B, Exeler JR et al: Chromosome abnormalities in 447 couples undergoing intracytoplasmic sperm injection - prevalence, types, sex distribution and reproductive relevance. Hum Reprod 1998; 13: 576-582.

19 Retief A, Van Zyl J, Menkveld M: Chromosome studies in 496 infertile males with a sperm count below 10 million per ml. Hum Genet 1984; 66: $162-164$.

20 Chandley AC, Hargreave TB: Genetic anomaly and ICSI. Hum Reprod 1996; 11: 930-932.

21 Van Assche E, Bonduelle M, Tournaye $\mathrm{H}$ et al: Cytogenetics of infertile men. Hum Reprod 1996; 11 (Suppl. 4): 1-24.

22 Yoshida A, Miura K, Shirai M: Cytogenetic survey of 1007 infertile men. Urol Int 1996; 58: 166-176.

23 Tuerlings JHAM, de France HF, Hamers A et al: Chromosome studies in 1792 males prior to intra-cytoplasmic sperm injection: the Dutch experience. Eur J Hum Genet 1998; 6: $194-200$.

24 Van der Ven K, Pescka B, Montag M et al: Increased frequency of congenital choromosomal aberrations in female partners of couples undergoing intracytoplasmic sperm injection. Hum Reprod 1998; 13: $48-54$. 
25 Antonelli A, Gandini L, Petrinelli P et al: Chromosomal alterations and male infertility. J Endocrinol Invest 2000; 23: $677-683$.

26 Egoczue S, Blanco J, Vendrell JM et al: Human male infertility: chromosome anomalies, meiotic disorders, abnormal spermatozoa and recurrent abortion. Hum Reprod Update 2000; 6: $93-$ 105.

27 Hargreave T: Genetically determined male infertility and assisted reproduction techniques. J Endocrinol Invest 2000; 23 $697-710$.

28 In't Veld P, Branderburg H, Verhoeff A: Sex chromosomal anomalies and intracytoplasmic sperm injection. Lancet 1995; 346: 773 .

29 Liebaers I, Bonduelle M, Legein J et al: Sex chromosome abnormalities after intracytoplasmic sperm injection. Lancet 1995; 346: 1095

30 Loft A, Petersen K, Erb K et al: A Danish cohort of 730 infants born after intracytoplasmic sperm injection (ICSI) 1994-1997. Hum Reprod 1999; 14: 2143-2148.

31 Tiepolo L, Zuffardi O: Localization of factors controlling spermatogenesis in the nonfluorescent portion of the human Y chromosome long arm.. Hum Genet 1976; 34: 119-124.

32 Foresta C, Ferlin A, Moro E: Deletion and expression analysis of AZFa-genes on the human Y chromosome revealed a major role for DBY in male infertility. Hum Mol Genet 2000; 9: 1161-1169.

33 Elliott DJ, Millar MR, Oghene K et al: Expression of RBM in the nuclei of human germ cells is dependent on a critical region of the Y chromosome long arm. Proc Natl Acad Sci USA 1997; 94: $3848-3853$.

34 Reijo R, Lee TY, Salo P et al: Diverse spermatogenic defects in humans caused by Y chromosome deletions encompassing a novel RNA-binding protein gene. Nat Genet 1995; 14: 292-299.

35 Lahn BT, Page DC: Functional coherence of the human Y chromosome. Science 1997; 278: 675-680.

36 Tilford CA, Kuroda-Kawaguchi T, Skaletski $\mathrm{H}$ et al: A physical map of the human Y chromosome. Nature 2001; 409: 943-945.

37 Foresta C, Moro E, Garolla A, Onisto M, Ferlin A: Y chromosome microdeletions in cryptorchidism and idiopathic infertility. $J$ Clin Endocrinol Metab 1999; 84: 3660 - 3665.

38 Krausz C, Quintana-Murci L, Barbaux S et al: A high frequency of $\mathrm{Y}$ chromosome deletions in males with nonidiopathic infertility. J Clin Endocrinol Metab 1999; 84: 3606-3612.

39 Moro E, Marin P, Rossi A, Garolla A, Ferlin A: Y chromosome microdeletions in infertile men with varicocele. Mol Cell Endocrinol 2000; 161: 67-71.

40 Chang PL, Sauer MV, Brown S: Y chromosome microdeletion in a father and his four infertile sons. Hum Reprod 1999; 14: 2689 2694.

41 Siffroi JP, Le Bourhis C, Krausz C et al: Sex chromosome mosaicism in males carrying $\mathrm{Y}$ chromosome long arm deletions. Hum Reprod 2000; 15: 2559-2562.

42 Claustres M, Guittard C, Bozon D et al: Spectrum of CFTR mutations in cystic fibrosis and in congenital absence of the vas deferens in France. Hum Mutat 2000; 16: 143-156.

43 Quinzii C, Castellani C: The cystic fibrosis transmembrane regulator gene and male infertility. J Endocrinol Invest 2000; 23 $684-689$.

44 Attardo T, Vicari E, Mollica F et al: Genetic, andrological and clinical characteristics of patients with congenital bilateral absence of the vas deferens. Int J Androl 2001; 24: 73 - 79.

45 Casals T, Bassas L, Egozcue S et al: Heterogeneity for mutations in the CFTR gene and clinical correlations in patients with congenital absence of the vas deferens. Hum Reprod 2000; 15 $1476-1483$

46 Mickle J, Milunsky A, Amos JA, Oates RD: Congenital unilateral absence of the vas deferens: a heterogeneous disorder with two distinct supopulations based upon aetiology and mutational status of the cystic fibrosis gene. Hum Reprod 1995; 10: 1728 1735 .
47 Dork T, Dworniczak B, Aulehla-Scholz C et al: Distinct spectrum of CFTR gene mutations in congenital absence of vas deferens. Hum Genet 1997; 100: 365 - 377.

48 Silber SJ, Nagy Z, Liu J et al: The use of epididymal and testicular spermatozoa for intracytoplasmic sperm injection: the genetic implications for male infertility. Hum Reprod 1995; 10: 2031 2043.

49 Hargreave TB: Genetically determined male infertility and assisted reproduction techniques. J Endocrinol Invest 2000; 23: $697-710$.

50 Seminara SB, Oliveira LMB, Beranova M, Hayes FJ, Crowley Jr WF: Genetics of hypogonadotropic hypogonadism. J Endocrinol Invest 2000; 23: 560-565.

51 Buchter D, Behre HM, Kliesch S, Nieschlag E: Pulsatile GnRH or human chorionic gonadotropin/human menopausal gonadotropin as effective treatment for men with hypoganodotropic hypogonadism: a review of 42 cases. Eur J Endocrinol 1998; 139: $298-303$.

52 Quigley CA, De Bellis A, Marschke KB, El-Awady MK, Wilson E, French FS: Androgen receptor defects: historical, clinical, and molecular perspective. Endocr Rev 1995; 16: 271-321.

53 Hiort O, Holterhus PM, Horter T et al: Significance of mutations in the androgen receptor gene in males with idiopathic infertility. J Clin Endocrinol Metab 2000; 85: 2810-2815.

54 Mifsud A, Sim CK, Boettger-Tong H et al: Trinucleotide (CAG) repeat polymorphisms in the androgen receptor gene: molecular markers of risk for male infertility. Fertil Steril 2001; 75: $275-281$.

55 Patrizio P, Leonard DG, Chen KL, Hernandez-Ayup S, Trounson AO: Larger trinucleotide repeat size in the androgen receptor gene of infertile men with extremely severe oligozoospermia. $J$ Androl 2001; 22: $444-448$.

56 Fratianni CM, Imperato-McGinley J: The syndrome of $5 \alpha$ reductase deficiency. Endocrinologist 1994; 4: 301-314.

57 Cai LQ, Fratianni CM, Gautier T, Imperato-McGinley J: Dihydrotestosterone regulation of semen in male pseudohermaprhoditism with $5 \alpha$-reductase- 2 deficiency. J Clin Endocrinol Metab 1994; 79: 409-414

58 Katz MD, Kligman I, Cai LQ et al: Paternity by intrauterine insemination with sperm from a man with $5 \alpha$-reductase-2 deficiency. N Engl J Med 1997; 336: 994-997.

59 Rosenbusch BE: Cytogenetics of human spermatozoa: what about the reproductive relevance of structural chromosome aberrations? J Assist Reprod Genet 1995; 12: 375 - 383.

60 Bernardini L, Gianaroli L, Fortini D et al: Frequency of hyper-, hypohaploidy and diploidy in ejaculate, epididymal and testicular germ cells of infertile patients. Hum Reprod 2000; 15: $2165-2172$

61 Vegetti W, Van Assche E, Frias A et al: Correlation between semen parameters and sperm aneuploidy rates investigated by fluorescence in-situ hybridization in infertile men. Hum Reprod 2000; 15: 351-365.

62 Calogero AE, De Palma A, Grazioso C et al: Aneuploidy rate in spermatozoa of selected men with abnormal semen parameters. Hum Reprod 2001; 16: $1172-1179$.

63 Robbins WA, Meistrich ML, Moore D et al: Chemotherapy induces transient sex chromosomal and autosomal aneuploidy in human sperm. Nat Genet 1997; 16: 74-78.

64 De Palma A, Vicari E, Palermo I, D'Agata R, Calogero AE: Effects of cancer and anti-neoplastic treatment on the human testicular function. J Endocrinol Invest 2000; 23: 690-696.

65 Baccetti B, Capitani S, Collodel G et al: Genetic sperm defects and consanguineity. Hum Reprod 2001; 16: $1365-1371$

66 Fauser BCJM, Hsueh AJW: Genetic basis of human repoductive endocrine disorders. Hum Reprod 1995; 10: 826-846.

67 Franks S, Gherani N, McCarthy M: Candidate genes in polycistic ovary syndrome. Hum Reprod Update 2001; 7: 405-410. 
68 Kao LC, Urbanek M, Driscoll D et al: The genetic basis of polycystic ovary sindrome. in Kovacs GT, ed. Polycystic ovary syndrome. Cambridge: Cambridge University Press, 2000, pp $35-48$.

69 Coway GS. Premature ovarian failure. Br Med Bullett 2000; 56: 643-649.

70 Plachot M. The human oocyte. Genetic aspects. Ann Genet 1997; 40: $115-120$

71 Ward KJ: Genetic factors in recurrent pregnancy loss. Semin Reprod Med 2000; 18: 425 - 432.

72 Badovinac R, Buretic-Tomljanovic A, Starcevic N, Kapovic M, Vlastelic I, Randic L: Chromosome studies in patients with defective reproductive success. Am J Reprod Immunol 2000; 44: $279-283$.

73 Goddijn M, Leschot NJ: Genetic aspects of miscarriage. Baillieres Best Pract Res Clin Obstet Gynaecol 2000; 14: 855 - 865.

74 Sherman SL: Premature ovarian failure among fragile $\mathrm{X}$ premutation carriers: parent-of-origin effect? Am J Hum Genet 2000; 67: $11-13$.

75 Sherman SL: Premature ovarian failure in the fragile $X$ syndrome. Am J Med Genet 2000; 97: 189-194.
76 Murray A, Ennis S, MacSwiney F, Webb J, Morton NE: Reproductive and menstrual history of females with fragile $\mathrm{X}$ expansions. Eur J Hum Genet 2000; 8: 247-252.

77 Ferraretti AP, Gianaroli L, Magli MC, Bafaro G, Colacurci N: Female poor responders. Mol Cell Endocrinol 2000; 161: 59-66.

78 Brandenberger AW, Haenggi W, von Fischer B, Birkhaeuser $\mathrm{MH}$ : Kallmann syndrome and associated malformations of the uterus. Fertil Steril 1994; 61: 395 - 397.

79 Zilberstein M, Seibel MA: Genetic issues in reproduction; in Seibel MA, (ed): Infertility: a comprehensive text. USA: Appleton \& Longe, Boston, 1997, pp $387-395$.

80 Butler WJ, McDonough PG: Molecular genetics and infertility; in: Seibel MA, (ed): Infertility: a comprehensive text. USA Appleton \& Longe, Boston, 1997, pp 371-385.

81 Lawler AM, Gearhart JD: Genetic counselling for patients who will be undergoing treatmnent with assisted reproductive technology. Fertil Steril 70: $412-413$.

82 Johnson MD: Genetic risks of intracytoplasmic sperm injection in the treatment of male infertilità: recommendations for genetic counselling and screening. Fertil Steril 1998; 70: 397 411. 